Научная статья

УДК 336.64

DOI: $10.17213 / 2075-2067-2021-5-148-155$

\title{
ОПТИМИЗАЦИЯ ФИНАНСОВОЙ ПОЛИТИКИ СЕЛЬСКОХОЗЯЙСТВЕННОЙ ОРГАНИЗАЦИИ
}

\author{
Ирина Борисовна Рудская ${ }^{\square,}$ \\ Наталья Николаевна Шукшина ${ }^{2}$, Анастасия Геннадьевна Миргород \\ 1, 2, 3 Азово-Черноморский инженерный институт, \\ Донской государственный аграрный университет, Зерноград, Россия

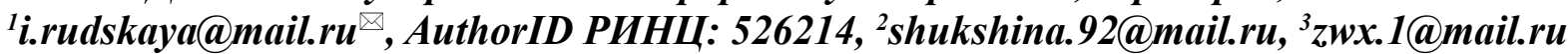

Аннотация. Целью исследования является оптимизация финансовой политики организащии для сокращчения ее финансовых рисков и обеспечения устойчивости функционирования.

Методологическую базу исследования представляют классические методы научных исследований: аналитический, абстрактно-логический, интерпретаџии, статистико-экономический, графический.

Результаты исследования. В ходе проведения финансового анализа результатов деятельности сельскохозяйственной организачии ОАО «Конный завод имени Первой Конной Армии» были выявлены финансовые риски, угрожающие ее финансовой безопасности. Минимизачия выявленных рисков основана на использовании ОАО «Конный завод имени Первой Конной армии» умеренной финансовой политики вместо агрессивной.

Перспективу исследования составляет практическая реализаџия предложенных направлений и фиксащия последующей динамики показателей финансовой устойчивости и платёжеспособности рассматриваемой организации, а также проведение диагностики типа финансовой политики других сельскохозяйственных организаџий с целью разработки мероприятий по ее оптимизации.

Ключевые слова: финансовая политика, финансовые риски, сельское хозяйство, собственный капитал, заемный капитал

Для цитирования: Рудская И.Б., Шукшина Н.Н., Миргород А.Г. Оптимизаџия финансовой политики сельскохозяйственной организаџии // Вестник Южно-Российского государственного технического университета. Серия: Социально-экономические науки. 2021. T. 14, №5. C. 148-155. http://dx.doi.org/10.17213/2075-2067-2021-5-148-155.

Original article

\section{OPTIMIZING THE FINANCIAL POLICY OF AGRICULTURAL ORGANIZATION}

\author{
Irina B. Rudskaya ${ }^{1 凶}$, Natalia N. Shukshina ${ }^{2}$,Anastasia G. Mirgorod ${ }^{3}$
}

1, 2, 3 Azov-Black Sea Engineering Institute, Don State Agrarian University, Zernograd, Russia ${ }^{1}$ i.rudskaya@mail.ru ${ }^{\bowtie}$,AuthorID RSCI: 526214, ${ }^{2}$ shukshina.92@mail.ru, ${ }^{3}$ zwx.1@mail.ru

(С) Рудская И.Б., Шукшина Н.Н., Миргород А.Г., 2021 
Abstract. The purpose of the study is to optimize the financial policy of the organization to reduce its financial risks and ensure the sustainability of its functioning.

The methodological basis of the research is represented by the classical methods of scientific research: analytical, abstract-logical, interpretation, statistical and economic, graphic.

Research results. In the course of the financial analysis of the results of the activities of the agricultural organization OJSC «Horse Factory named after the First Horse Army», financial risks were identified that threaten its financial security. The minimization of the identified risks is based on the use of a moderate financial policy instead of an aggressive one by OJSC "Horse Factory named after the First Cavalry Army».

The prospect of the study is the practical implementation of the proposed directions and the fixation of the subsequent dynamics of indicators of financial stability and solvency of the organization in question, as well as diagnostics of the type of financial policy of other agricultural organizations in order to develop measures to optimize it.

Keywords: financial policy, financial risks, agriculture, equity capital, debt capital

For citation: Rudskaya I.B., Shukshina N.N., Mirgorod A.G. Optimizing the financial policy of agricultural organization // Bulletin of the South Russian State Technical University. Series: Socio-economic Sciences. 2021; 14(5): 148-155. (In Russ.). http://dx.doi.o rg/10.17213/2075-2067-2021-5-148-155.

Введение. Целью разработки финансовой политики организации является построение эффективной системы управления финансами, направленной на достижение ее стратегических и тактических задач. Выбор нерациональной, неэффективной финансовой политики может привести к потере организацией своей финансовой независимости, ухудшению финансовых результатов деятельности, показателей финансовой устойчивости, платежеспособности и ликвидности организации $[1 ; 6]$.

Методика. Информационной, методической и теоретической основой настоящего исследования послужили труды специалистов в области финансового анализа деятельности сельскохозяйственных предприятий [4-10]. В ходе исследования применялись классические методы научных исследований: аналитический, абстрактно-логический, интерпретации, статистико-экономический, графический.

Результаты исследования. В ходе проведения анализа финансового состояния ОАО «Конный завод имени Первой Конной Армии» Зерноградского района Ростовской области были установлены финансовые риски, систематизированные в виде рис. 1, под- тверждающие неэффективность действующей в организации финансовой политики.

Из рисунка 1 видно, что рассматриваемой сельскохозяйственной организации угрожает потеря финансовой автономии вследствие превалирования доли заемного капитала в общей совокупности источников финансирования организации. В среднем за исследуемый трехлетний период ОАО «Конный завод имени Первой Конной Армии» на 64,0\% финансировало свою деятельность за счет заемного капитала. Расширение финансирования благодаря использованию заемных средств может привести к увеличению коэффициента финансового левериджа, отражающего уровень финансового риска [3].

От оптимальности соотношения собственного капитала и заемного зависит финансовое состояние предприятия, а разработка правильной финансовой стратегии помогает увеличить эффективность производственнофинансовой деятельности $[2 ; 6]$.

Важным направлением улучшения финансовой устойчивости и платёжеспособности ОАО «Конный завод имени Первой Конной Армии» является оптимизация соотношения собственного и заемного капитала. Оценка различных вариантов структуры капитала анализируемой организации приведена в таблице 1 . Из таблицы 1 видно, что 


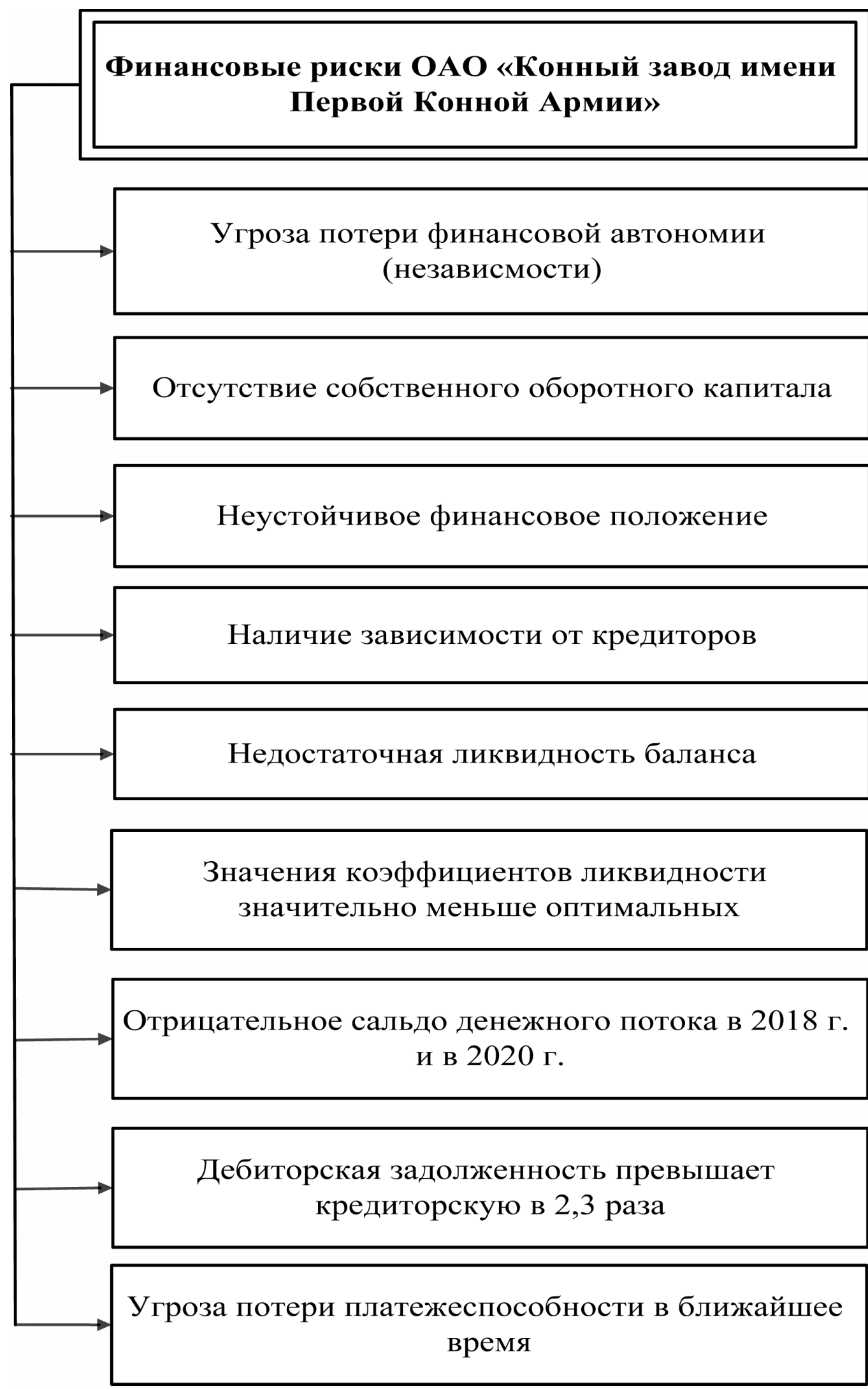

Рис. 1. Выявленные в ходе анализа финансовой устойчивости и платёжеспособности финансовые риски исследуемой организации

Fig. 1. The financial risks of the studied organization identified during the analysis of financial stability and solvency 
в качестве критерия оптимизации соотношения собственного и заемного капитала нами был использован обобщающий показатель, который, с одной стороны, учитывает интересы собственников предприятия, с другой - соединяет в себе частные показатели рентабельности и финансового риска, т.е. оценивали соотношение «рентабельность финансовый риск» (РР). Оптимальным считается тот вариант структуры источников капитала, в котором показатель РР будет иметь наибольшее значение (PР $\rightarrow \max )$. Срок окупаемости характеризует скорость возврата вложенного капитала и является еще одним критерием оценки, который также может быть использован для оптимизации структуры источников капитала.

В результате проведенных расчётов приходим к выводу, что при повышении доли заемного капитала растет и рентабельность использования собственных средств, но одновременно возрастает и уровень финансового риска. Рассматривая обобщающий показатель «рентабельность - риск», видно, что его максимального значения (36) ОАО «Конный завод имени Первой Конной Армии» может добиться при удельном весе заемного капитала $20 \%$, но, на наш взгляд, этой суммы заемных средств будет недостаточно для приобретения внеоборотных активов, запасов и для расширенного воспроизводства.

При удельном весе заемного капитала $80 \%$ показатель «рентабельность - риск» составит 30,882 , но такая доля заемного капитала влечет потерю финансовой независимости рассматриваемого предприятия, а также имеет следующие негативные моменты [4; 8]:

- привлечение заемных средств в больших объемах (в форме кредитов и займов) порождает наиболее опасные для организации финансовые риски: кредитный, процентный, риск потери ликвидности и др.;

- возникают дополнительные расходы по обслуживанию долга перед кредиторами;

- высокая зависимость стоимости заемного капитала от колебаний на кредитном рынке (особенно при долгосрочном заимствовании средств);

- сложность процедуры привлечения заемных средств (особенно в крупных размерах и на срок более одного года), так как предоставление кредитных ресурсов зависит от возможностей банков, требующих залога имущества, или солидарных гарантий других хозяйствующих субъектов.

Поэтому, с нашей точки зрения, наиболее оптимальное соотношение заемного и собственного капиталов находится в пропорции 40/60, при котором показатель «рентабельность - риск» составит 21,882.

Обсуждение. Полученные в ходе исследования результаты позволяют нам высказать свое мнение.

Вследствие присущей сельскохозяйственной деятельности сезонности производства у аграрных товаропроизводителей постоянно возникает потребность в заемном капитале. Однако, превалирование доли заемных средств в общем объеме финансирования может привести к увеличению зависимости от кредиторов и потере предприятием финансовой автономии. Доля заемных средств, на наш взгляд, не должна превышать $50 \%$ в структуре капитала сельскохозяйственной организации. При выборе оптимального соотношения собственного и заемного капитала необходимо учитывать соотношение «рентабельность - риск».

Заключение. В ходе проведенного финансового анализа было установлено, что деятельности ОАО «Конный завод имени Первой Конной Армии» присущи весьма существенные финансовые риски, угрожающие его финансовой автономии, из этого авторы пришли к выводу о нерациональности проводимой агрессивной финансовой политики. Проведя расчеты различных вариантов финансирования деятельности анализируемой организации, выяснили, что наиболее оптимальное соотношение заемного и собственного капиталов находится в пропорции 40/60, при котором показатель «рентабельность риск» составит 21,882. По нашему мнению, ОАО «Конный завод имени Первой Конной Армии» целесообразно применять умеренную финансовую политику, оптимизировать объем заемного капитала и дебиторской задолженности. Реализация предложенных рекомендаций будет способствовать повышению финансовой устойчивости, ликвидности и платежеспособности анализируемого пред- 


\begin{tabular}{|c|c|c|c|c|c|c|c|c|c|c|c|c|}
\hline \multirow{8}{*}{ 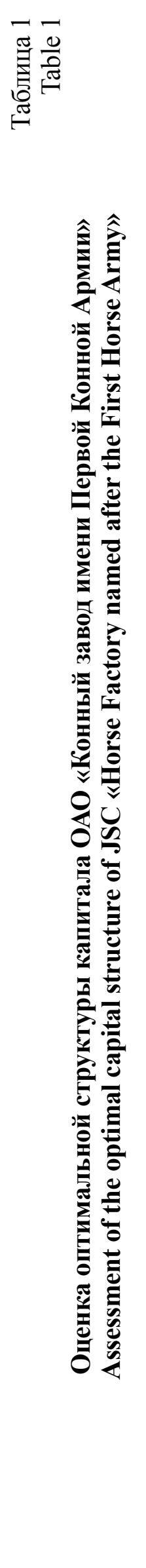 } & \multirow{7}{*}{ 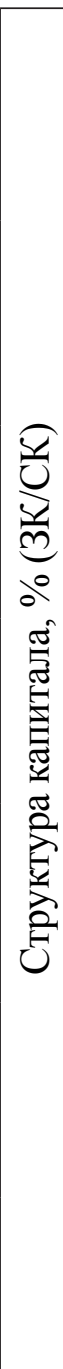 } & 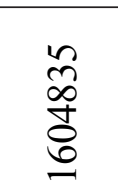 & 0 & 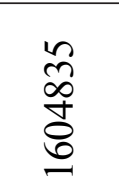 & 1 & $\underset{0}{\stackrel{N}{0}}$ & $\begin{array}{l}\exists \\
\frac{\sqrt{n}}{\sigma}\end{array}$ & $\overbrace{0}^{N}$ & 1 & 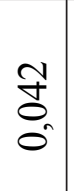 & 1 & 1 \\
\hline & & $\begin{array}{l}n \\
\infty \\
\infty \\
0 \\
0\end{array}$ & $\begin{array}{l}\text { ல̊ } \\
\text { ᄋे } \\
\text { nి }\end{array}$ & $\begin{array}{l}\infty \\
\infty \\
\infty \\
\infty \\
\infty \\
\end{array}$ & 1 & $\underset{O}{\stackrel{N}{O}}$ & $\frac{\Xi}{\stackrel{\Xi}{r}}$ & $\tilde{\sigma}^{n}$ & $\stackrel{n}{\circ}$ & 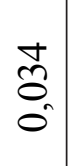 & $\begin{array}{l}\infty \\
\infty \\
\infty \\
\infty \\
\infty\end{array}$ & $\stackrel{\infty}{+}$ \\
\hline & & \begin{tabular}{l}
$\mathscr{n}$ \\
$\infty$ \\
\multirow{0}{0}{}
\end{tabular} & 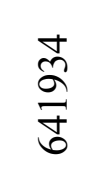 & 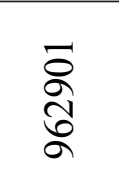 & 1 & $\underset{O}{\stackrel{I}{O}}$ & \begin{tabular}{l}
$\exists$ \\
$\stackrel{\Xi}{\sigma}$ \\
\multirow{\sigma}{*}{}
\end{tabular} & $\tilde{\sigma}^{\prime}$ & 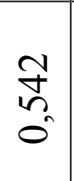 & 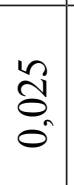 & $\begin{array}{l}\infty \\
\dot{0} \\
\vec{i}\end{array}$ & $\begin{array}{l}0 \\
\forall\end{array}$ \\
\hline & & $\begin{array}{l}n \\
\tilde{\infty} \\
0 \\
0 \\
0\end{array}$ & $\begin{array}{l}\frac{\infty}{\mathbb{J}} \\
\underset{\infty}{\infty}\end{array}$ & $\frac{\infty}{\underset{d}{J}}$ & 1 & $\begin{array}{l}\mathcal{Y} \\
\stackrel{O}{0}\end{array}$ & $\begin{array}{l}\Xi \\
\stackrel{\Xi}{\sigma}\end{array}$ & $\tilde{\sigma}^{n}$ & $\underset{\sim}{f_{0}}$ & $\begin{array}{l}\vec{\sigma} \\
\sigma_{0}\end{array}$ & $\begin{array}{l}\hat{n} \\
\hat{\tilde{\nu}} \\
\hat{\tilde{N}}\end{array}$ & $\stackrel{n}{*}$ \\
\hline & & 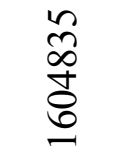 & $\begin{array}{l}\text { 응 } \\
\text { तु }\end{array}$ & $\begin{array}{l}\stackrel{J}{\sigma} \\
\frac{\sigma}{\sigma}\end{array}$ & 1 & $\underset{O}{\stackrel{N}{O}}$ & $\underset{⿱ 亠}{\stackrel{\Xi}{\sigma}}$ & $\tilde{\sigma}^{n}$ & 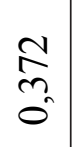 & $\begin{array}{l}0 \\
0 \\
0\end{array}$ & $\begin{array}{l}\infty \\
\infty \\
\infty \\
\vec{\sim}\end{array}$ & $\stackrel{n}{*}$ \\
\hline & & 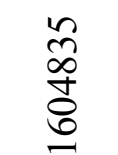 & $\begin{array}{l}\infty \\
0 \\
\infty \\
⿱ 亠 \\
\infty \\
\end{array}$ & $\begin{array}{l}\hat{0} \\
\text { ᄋे } \\
\text { nి }\end{array}$ & I & $\underset{0}{\stackrel{N}{J}}$ & $\begin{array}{l}\exists \\
\underset{\sim}{\sim}\end{array}$ & $\tilde{\sigma}^{n}$ & $\begin{array}{l}\infty \\
\infty \\
\\
0\end{array}$ & $\begin{array}{l}\infty \\
8 \\
0 \\
0\end{array}$ & r & $\stackrel{n}{*}$ \\
\hline & & 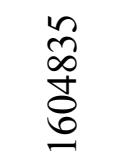 & 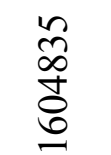 & 0 & 1 & $\underset{O}{\stackrel{Y}{O}}$ & $\begin{array}{l}\exists \\
\underset{\sim}{\sim}\end{array}$ & $\overbrace{0}^{n}$ & $\stackrel{\hat{n}}{\hat{\sigma}}$ & 1 & 1 & $\stackrel{\sim}{\gamma}$ \\
\hline & 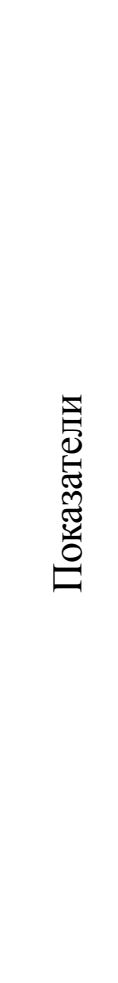 & 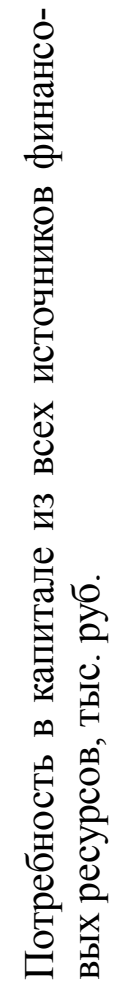 & 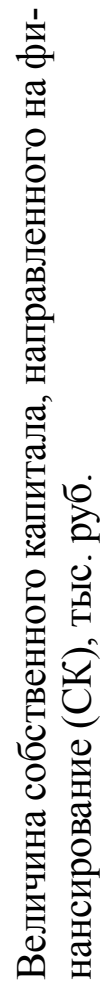 & 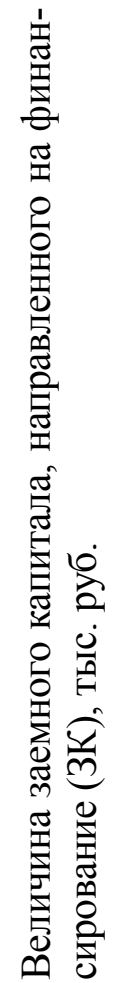 & 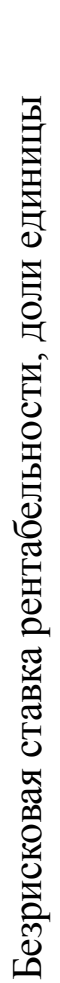 & 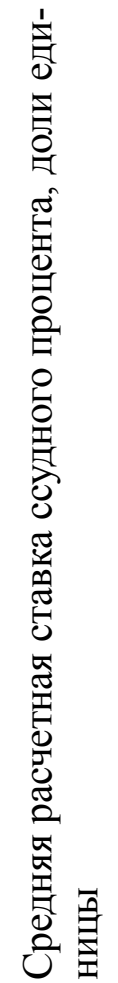 & 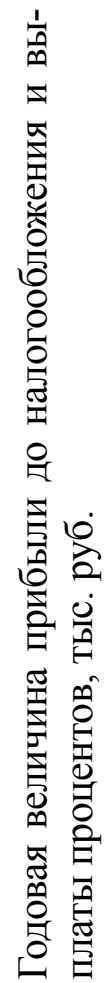 & 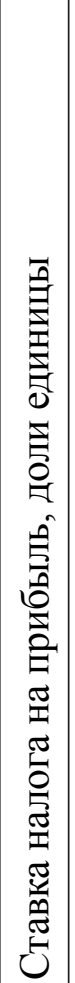 & 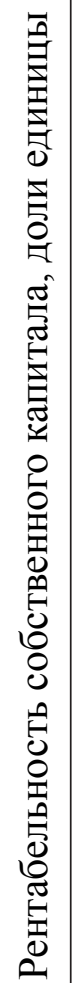 & 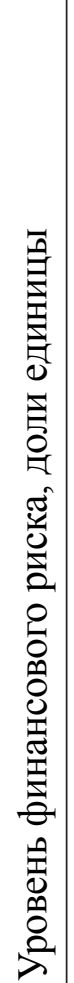 & 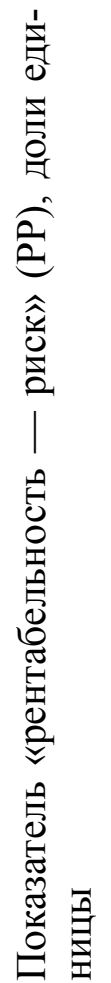 & 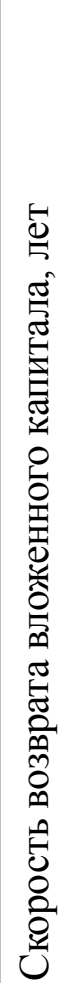 \\
\hline
\end{tabular}


приятия, минимизации финансовых рисков и достижению оптимального уровня его финансовой безопасности.

\section{Список источников}

1. Коновалова У.Е. Улучшение финансовой устойчивости и платежеспособности предприятия // Современная экономика: проблемы, пути решения, перспективы. Самарский государственный аграрный университет. Самара: Кинель, 2020. С. 189-192.

2. Рудская И.Б., Головина Д.В. Анализ финансовых результатов деятельности агропредприятий // Учет, анализ и аудит: новые задачи в обеспечении безопасности и ответственность перед бизнесом. М.: РУСАЙНС, 2020. С. 145-154.

3. Рудская И. Б., Шукшина Н.Н. Диагностика уровня финансовой устойчивости организации АПК // Роль налогового планирования и учетно-аналитического обеспечения в безопасности функционирования хозяйствующих субъектов. М.: РУСАЙНС, 2021. С. 581-589.

4. Савицкая Г.В. Проблемные аспекты определения эффекта финансового рычага // Экономический анализ: теория и практика. M., 2016. №5. C. 99-111.

5. Соколова В.П. Экономико-математические методы для анализа финансового состояния предприятия // Сборник научных трудов международной научно-практической конференции «Человек, общество и государство в современном мире». Пенза: Пензенский государственный технологический университет, 2016. С. 194-198.

6. Тагирова О.А., Пестова О.Н. Анализ реализации финансовой политики сельскохозяйственной организации // Сурский вестник. Пенза: Пензенский государственный технологический университет, 2020. №3 (11). C. $92-99$.

7. Хамбулатова 3.Р. Теоретические основы анализа финансовой устойчивости и платежеспособности предприятия // Актуальные вопросы современной экономики. Махачкала: Институт развития образования и консалтинга, 2020. №4. С. 76-81.

8. Хаупшева Д.М. Финансовый анализ как методика управления платежеспособностью и финансовой устойчивостью // На- учные записки молодых исследователей. М.: Финансовый университет при Правительстве РФ, 2017. №4. С. 11-15.

9. Kirpikov A.N., Nugaev F. S. Relevant approaches to performing analysis of financial results of organization's activity with application of factor models // International Business Management. Emerald Group Publishing Ltd., 2016. P. 98-101.

10. Zimakova L.A., Kovalevskaja A. V. Phases of Evaluation of Projected Financial Resultsfrom Ordinary Activities of a Manufacturing Company // International Business. Medwell Jornals, 2016. P. 137-142.

\section{References}

1. Konovalova U.E. Uluchshenie finansovoj ustojchivosti i platezhesposobnosti predprijatija [Improving the financial stability and solvency of the enterprise]. Sovremennaja jekonomika: problemy, puti reshenija, perspektivy. Camarskij gosudarstvennyj agrarnyj universitet [Modern economy: problems, solutions, prospects. Samara State Agrarian University]. Samara: Kinel', 2020; 189-192. (In Russ.).

2. Rudskaja I. B., Golovina D. V. Analiz finansovyh rezul'tatov dejatel'nosti agropredprijatij [Analysis of financial results of agricultural enterprises' activities]. Uchet, analiz i audit: novye zadachi $\mathrm{v}$ obespechenii bezopasnosti i otvetstvennost' pered biznesom [Accounting, analysis and audit: new tasks in ensuring security and responsibility to business]. Moscow: RUSAJNS, 2020; 145-154. (In Russ.).

3. Rudskaja I. B., Shukshina N. N. Diagnostika urovnja finansovoj ustojchivosti organizacii APK [Diagnostics of the level of financial stability of the agro-industrial complex organization]. Rol' nalogovogo planirovanija i uchetnoanaliticheskogo obespechenija $\mathrm{v}$ bezopasnosti funkcionirovanija hozjajstvujushhih sub'ektov [The role of tax planning and accounting and analytical support in the safety of the functioning of economic entities]. Moscow: RUSAJNS, 2021; 581-589. (In Russ.).

4. Savickaja G. V. Problemnye aspekty opredelenija jeffekta finansovogo rychaga [Problematic aspects of determining the effect of financial leverage]. Jekonomicheskij analiz: teorija $i$ praktika [Economic analysis: theory and practice]. Moscow, 2016; 5: 99-111. (In Russ.). 
5. Sokolova V.P. Jekonomiko-matematicheskie metody dlja analiza finansovogo sostojanija predprijatija [Economic and mathematical methods for analyzing the financial condition of an enterprise]. Sbornik nauchnyh trudov mezhdunarodnoj nauchno-prakticheskoj konferencii «Chelovek, obshhestvo i gosudarstvo v sovremennom mire» [Collection of scientific papers of the international scientific and practical conference «Man, society and the state in the modern world»]. Penza: Penzenskij gosudarstvennyj tehnologicheskij universitet, 2016; 194-198. (In Russ.).

6. Tagirova O.A., Pestova O.N. Analiz realizacii finansovoj politiki sel'skohozjajstvennoj organizacii [Analysis of the implementation of the financial policy of an agricultural organization]. Surskij vestnik [Sursky Vestnik]. Penza: Penzenskij gosudarstvennyj tehnologicheskij universitet, 2020; 3 (11): 92-99. (In Russ.).

7. Hambulatova Z.R. Teoreticheskie osnovy analiza finansovoj ustojchivosti i platezhesposobnosti predprijatija [Theoretical foundations of the analysis of financial stability and solvency of the enterprise]. Aktual'nye voprosy sovremennoj jekonomiki [Current issues of the modern econo$m y$ ]. Mahachkala: Institut razvitija obrazovanija i konsaltinga, 2020; 4: 76-81. (In Russ.).

8. Haupsheva D. M. Finansovyj analiz kak metodika upravlenija platezhesposobnost'ju i finansovoj ustojchivost'ju [Financial analysis as a method of managing solvency and financial stability]. Nauchnye zapiski molodyh issledovatelej [Scientific notes of young researchers]. Moscow: Finansovyj universitet pri Pravitel'stve RF, 2017; 4: 11-15. (In Russ.).

9. Kirpikov A. N., Nugaev F. S. Relevant approaches to performing analysis of financial results of organization's activity with application of factor models // International Business Management. Emerald Group Publishing Ltd., 2016. P. 98-101.

10. Zimakova L.A., Kovalevskaja A.V. Phases of Evaluation of Projected Financial Resultsfrom Ordinary Activities of a Manufacturing Company // International Business. Medwell Jornals, 2016. P. 137-142.

Статья поступила в редакиию 02.09.2021; одобрена после рецензирования 12.09.2021; принята к публикачии 25.09.2021.

The article was submitted on 02.09.2021; approved after reviewing on 12.09.2021; accepted for publication on 25.09.2021.

\section{ИНФОРМАЦИЯ ОБ АВТОРАХ}

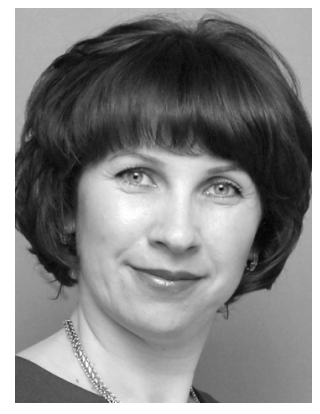

Рудская Ирина Борисовна - кандидат экономических наук, доцент кафедры «Бухгалтерский учет, анализ и аудит», Азово-Черноморский инженерный институт, Донской государственный аграрный университет.

Россия, г. Зерноград, ул. Ленина, 21

Irina B. Rudskaya - Candidate of Economic Sciences, Associate Professor of the Department of Accounting, Analysis and Audit, Azov-Black Sea Engineering Institute, Don State Agrarian University.

21 Lenin st., Russia, Zernograd 


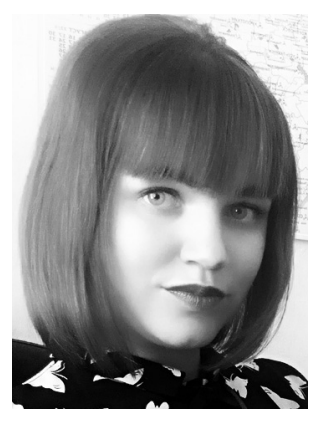

Шукшина Наталья Николаевна - магистрант, направление подготовки «Экономика», Азово-Черноморский инженерный институт, Донской государственный аграрный университет.

Россия, г. Зерноград, ул. Ленина, 21

Natalya N. Shukshina - Master's Student, direction of training «Economics», Azov-Black Sea Engineering Institute, Don State Agrarian University.

21 Lenin st., Russia, Zernograd

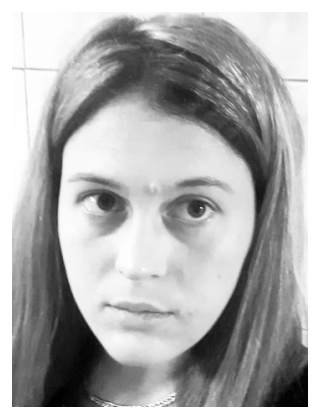

Миргород Анастасия Геннадьевна - магистрант, направление подготовки «Экономика», Азово-Черноморский инженерный институт, Донской государственный аграрный университет.

Россия, г. Зерноград, ул. Ленина, 21

Anastasia G. Mirgorod - Master's Student, direction of training «Economics», Azov-Black Sea Engineering Institute, Don State Agrarian University.

21 Lenin st., Russia, Zernograd

\section{Вклад авторов:}

Рудская И.Б. - научное руководство; концепция исследования; развитие методологии; написание исходного текста; итоговые выводы.

Шукиина Н.Н. - исследование финансовых рисков анализируемой организации, итоговые выводы.

Миргород А. Г. - определение оптимальной структуры капитала исследуемой организации, итоговые выводы.

Contribution of the authors:

Rudskaya I. B. - scientific leadership; research concept; development of methodology; writing the source text; final conclusions.

Shukshina N.N. - research of financial risks of the analyzed organization, final conclusions. Mirgorod A. G. - determination of the optimal capital structure of the studied organization, final conclusions. 